Check for updates

Cite this: RSC Adv., 2020, 10, 31425

Received 5th August 2020

Accepted 20th August 2020

DOI: $10.1039 / \mathrm{d} 0 \mathrm{ra06745h}$

rsc.li/rsc-advances

\section{Theoretical investigation on the nature of 4- substituted Hantzsch esters as alkylation agents}

\begin{abstract}
Guang-Bin Shen, (DD ${ }^{a}$ Li Xie, $^{a}$ Hao-Yun Yu, ${ }^{a}$ Jie Liu, ${ }^{a}$ Yan-Hua Fu ${ }^{b}$ and Maocai Yan (D) *c
Recently, a variety of 4-substituted Hantzsch esters $(\mathrm{XRH})$ with different structures have been widely researched as alkylation reagents in chemical reactions, and the key step of the chemical process is the elementary step of $\mathrm{XRH}^{\cdot+}$ releasing $\mathrm{R}^{*}$. The purpose of this work is to investigate the essential factors which determine whether or not an $\mathrm{XRH}$ is a great alkylation reagent using density functional theory (DFT). This study shows that the ability of an XRH acting as an alkylation reagent can be reasonably estimated by its $\Delta G_{\mathrm{RD}}\left(\mathrm{XRH}^{\cdot+}\right)$ value, which can be conveniently obtained through DFT computations. Moreover, the data also show that $\Delta G_{\mathrm{RD}}^{\neq}\left(\mathrm{XRH}^{\cdot+}\right)$ has no simple correlation with the structural features of $\mathrm{XRH}$, including the electronegativity of the $\mathrm{R}$ substituent group and the magnitude of steric resistance; therefore, it is difficult to judge whether an $\mathrm{XRH}$ can provide $\mathrm{R}^{\cdot}$ solely by experience. Thus, these results are helpful for chemists to design 4-substituted Hantzsch esters $(\mathrm{XRH})$ with novel structures and to guide the application of $\mathrm{XRH}$ as a free radical precursor in organic synthesis.
\end{abstract}

\section{Introduction}

It is well known that the Hantzsch ester $\left(\mathrm{HEH}_{2}\right.$, Scheme 1) was first synthesized by Hantzsch, a German chemist, in $1881 .^{1}$ Due to the simple synthesis method and excellent reduction performance, $\mathrm{HEH}_{2}$ has long been used as an organic hydrogen molecular reductant to hydrogenate various types of unsaturated compounds. ${ }^{2-4} \mathrm{HEH}_{2}$ releases two hydrogen atoms or hydrogen ions to unsaturated substrates while itself aromatizes into pyridine compounds, meanwhile the unsaturated bonds $(\mathrm{C}=\mathrm{C}, \mathrm{C}=\mathrm{N}, \mathrm{C}=\mathrm{O}$, etc.) in the substrates are reduced. Organic synthetic chemists have done excellent research work in designing novel catalysts, expanding new reaction substrate and improving product chirality and yield using $\mathrm{HEH}_{2}$ as reducer. Since 2013, chemists found that 4-substituted Hantzsch esters (XRH, Scheme 1) can break $\mathrm{C}-\mathrm{C}$ bond and release alkyl radical $\left(\mathrm{R}^{\circ}\right)$ under the condition of photocatalysis. ${ }^{5}$ Then $\mathrm{R}^{\bullet}$ reacts with electron-activated substrate to produce alkyl substitution or alkyl addition products, and hundreds of literatures have reported the alkylation reaction between XRH with various substrates. ${ }^{6-18}$

There are two main mechanisms (Scheme 2) for the reactions of XRH as alkylating agents reacting with substrates. Under certain specific wavelength, the photocatalyst (PC) is activated into an excited state photocatalyst ( $\left.\mathrm{PC}^{*}\right)$ with strong single

${ }^{a}$ School of Medical Engineering, Jining Medical University, Jining, Shandong, 272000, P. R. China

${ }^{b}$ College of Chemistry and Environmental Engineering, Anyang Institute of Technology, Anyang, Henan, 455000, P. R. China

${ }^{c}$ School of Pharmacy, Jining Medical University, Rizhao, Shandong, 276800, P. R. China.E-mail:maocaiyan@mail.jnmc.edu.cn electron oxidation ability. $\mathrm{PC}^{*}$ oxidizes $\mathrm{XRH}$ to $\mathrm{XRH}^{{ }^{+}}$and transforms itself into $\mathrm{PC}^{\cdot-}$, a strong single electron reducer. $\mathrm{XRH}^{\cdot+}$ is an unstable and active key intermediate, which will release $\mathrm{R}^{\cdot}$ to substrate. The first mechanism ${ }^{7-12}$ is that $\mathrm{PC}^{\cdot-}$ reduces the reaction substrate $\left(R_{1}-G\right)$ to $R_{1}-G^{\cdot-}$, subsequently, $R_{1}-G^{\cdot-}$ releases stable $G^{-}$group to generate $R_{1}{ }^{\circ}$. Recombination of $R^{\cdot}$ and $R_{1} \cdot$ radicals generates the desired product $R_{1}-R$. Since the concentrations of $\mathrm{R}^{*}$ and $\mathrm{R}_{1}{ }^{*}$ are very low in solution, hydrogen-abstraction by the radicals may possibly occur as a side-reaction (Mechanism 1 in Scheme 2). Alkylation of haloalkanes is a typical reaction of this mechanism. The second mechanism ${ }^{\mathbf{1 3 - 1 8}}$ is that $\mathrm{R}^{\cdot}$ reacts with unsaturated substrate (such as $R_{2}=R_{2}$ ) to form active free radical intermediate $R_{2}-$ $\mathrm{R}_{2}{ }^{\cdot}$ first, then $\mathrm{RR}_{2}-\mathrm{R}_{2}{ }^{\circ}$ obtains electrons from $\mathrm{PC}^{\cdot-}$ and protons from $\mathrm{XH}^{+}$to form alkylation product $\mathrm{RR}_{2}-\mathrm{R}_{2} \mathrm{H}$ (Mechanism 2 in Scheme 2). After carefully analyzing the reaction mechanism of $\mathrm{XRH}$ acting as alkylating reagents, it is clear that the key step is the elementary step of $\mathrm{XRH}^{\cdot+}$ releasing $\mathrm{R}^{\cdot}$ (Scheme 3), but not all $\mathrm{XRH}$ with various $\mathrm{R}$ substituent groups in 4-position can give the alkyl radicals, for example, 4 - $\mathrm{Ph}-\mathrm{HEH}$ cannot provide $\mathrm{Ph}^{\circ}$ in alkylation reaction.<smiles>CCOC(=O)C1=C(C)N(P)C(C(=O)OCC)=C(C)N1</smiles><smiles>[R]C1=C(C(=O)OCC)C([R])C(C(=O)OCC)=C(C)N1</smiles>

Scheme 1 Structures of $\mathrm{HEH}_{2}$ and $\mathrm{XRH}$ investigated in this work. 

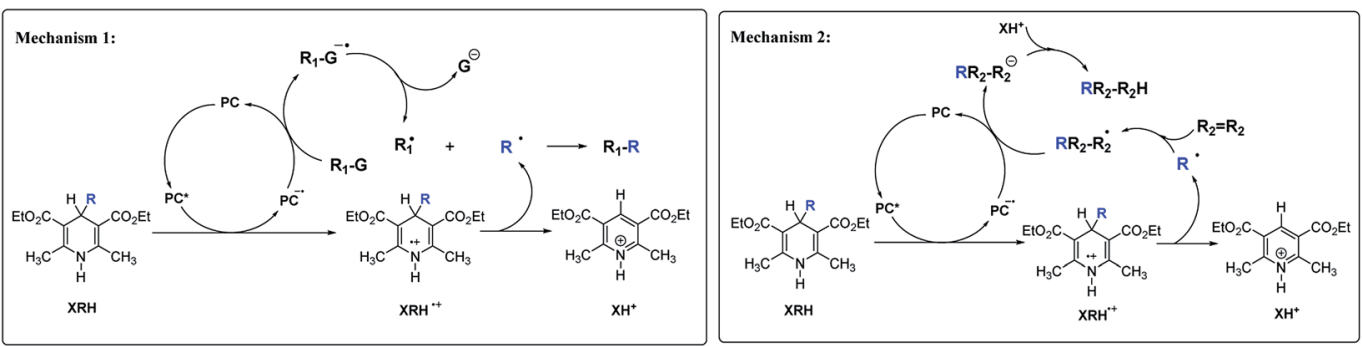

Scheme 2 Two mechanisms of $\mathrm{XRH}$ being used as alkylation reagents in chemical reactions.

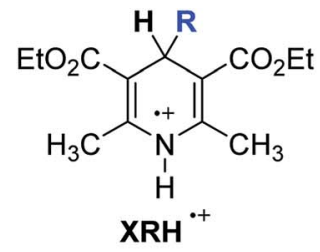
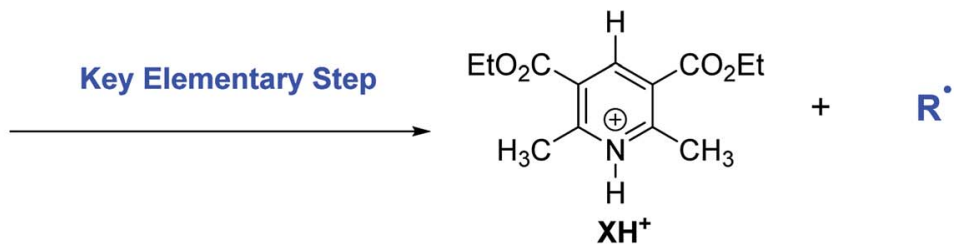

Scheme 3 Key elementary step of XRH being used as alkylation reagents in chemical reactions.

Then we begin to wonder: why some structures of XRH $(\mathrm{R}=$ $\mathrm{Bn}$, tert-Bu, cyclohexyl, allyl, etc.) are excellent alkylation reagents, while some structures of XRH $(\mathrm{R}=\mathrm{Ph}$, thienyl, etc. $)$ cannot be used as alkylation reagents, and what determines whether an XRH can be a good alkylation reagent? At present, the above question have not been well answered, and it is difficult to determine these important thermodynamic and kinetic data by experimental methods. Therefore, there is an urgent need for an accurate and reliable theoretical method to guide the experimental design in the field of organic synthesis. Further study on the thermodynamic and kinetic properties of the key intermediate $\mathrm{XRH}^{++}$releasing $\mathrm{R}^{\cdot}$ can guide chemists to better design 4-substituted Hantzsch esters (XRH) as novel alkylation reagents and understand the alkylation mechanism in organic synthesis.

Owing to the rapid development of density functional theory $(\mathrm{DFT})^{19-23}$ in recent years and the large enhancement of computational capability, the thermodynamic driving forces and activation energies of chemical reactions could be accurately computed by employing suitable density functionals. Based on the important structure of 4-substituted Hantzsch esters (XRH) reported in previous literatures, $17 \mathrm{XRH}$ have been well-designed in this work (Scheme 4). The thermodynamic driving forces [free energy change, $\Delta G_{\mathrm{RD}}^{\mathrm{o}}\left(\mathrm{XRH}^{\cdot+}\right)$ ] and activation Gibbs free energies $\left[\Delta G_{\mathrm{RD}}^{\neq}\left(\mathrm{XRH}^{+}\right)\right]$of different structures of $\mathrm{XRH}^{++}$releasing $\mathrm{R}^{\cdot}$ were computed using DFT, and the essential factors determining whether or not an XRH is alkylation reagent have been revealed in detail in this work.

\section{Computational section}

Molar free energy change of $\mathrm{XRH}^{+}$releasing $\mathrm{R}^{\cdot}$ $\left[\Delta G_{\mathrm{RD}}^{\mathrm{o}}\left(\mathrm{XRH}^{{ }^{+}}\right)\right]$, molar enthalpy changes of $\mathrm{XRH}^{++}$releasing $\mathrm{R}^{\cdot}$
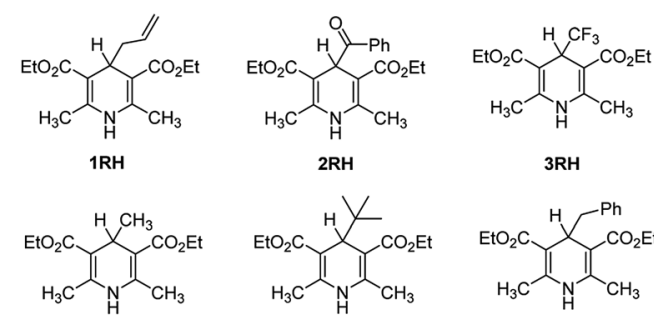

8RH

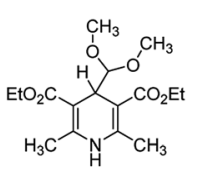

13RH

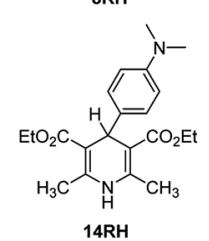

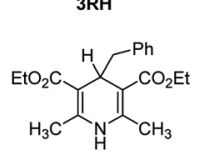

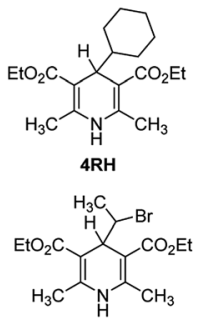

10RH

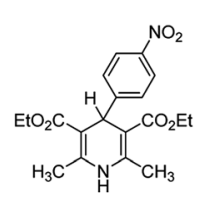

$15 \mathrm{RH}$<smiles>CCOC(=O)C1=C(C)NC(C)=C(C(CC)OCC)C1c1ccccc1</smiles>

16 RH

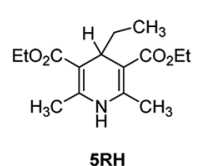<smiles>CCOC(=O)C1=C(C)NC(C)=C(C(=O)OCC)C1C(C)C</smiles><smiles>CCOC(=O)C1=C(C)NC(C)=C(C(=O)OCC)C1CNC(=O)c1ccccc1</smiles>

11RH

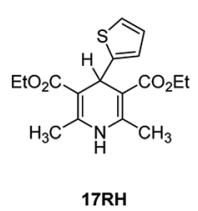

Scheme 4 Chemical structures of $17 \mathrm{XRH}$ examined in this work. 
Table 1 Comparison between DFT calculation data and experimental data $\left(\mathrm{kcal} \mathrm{mol}^{-1}\right)$

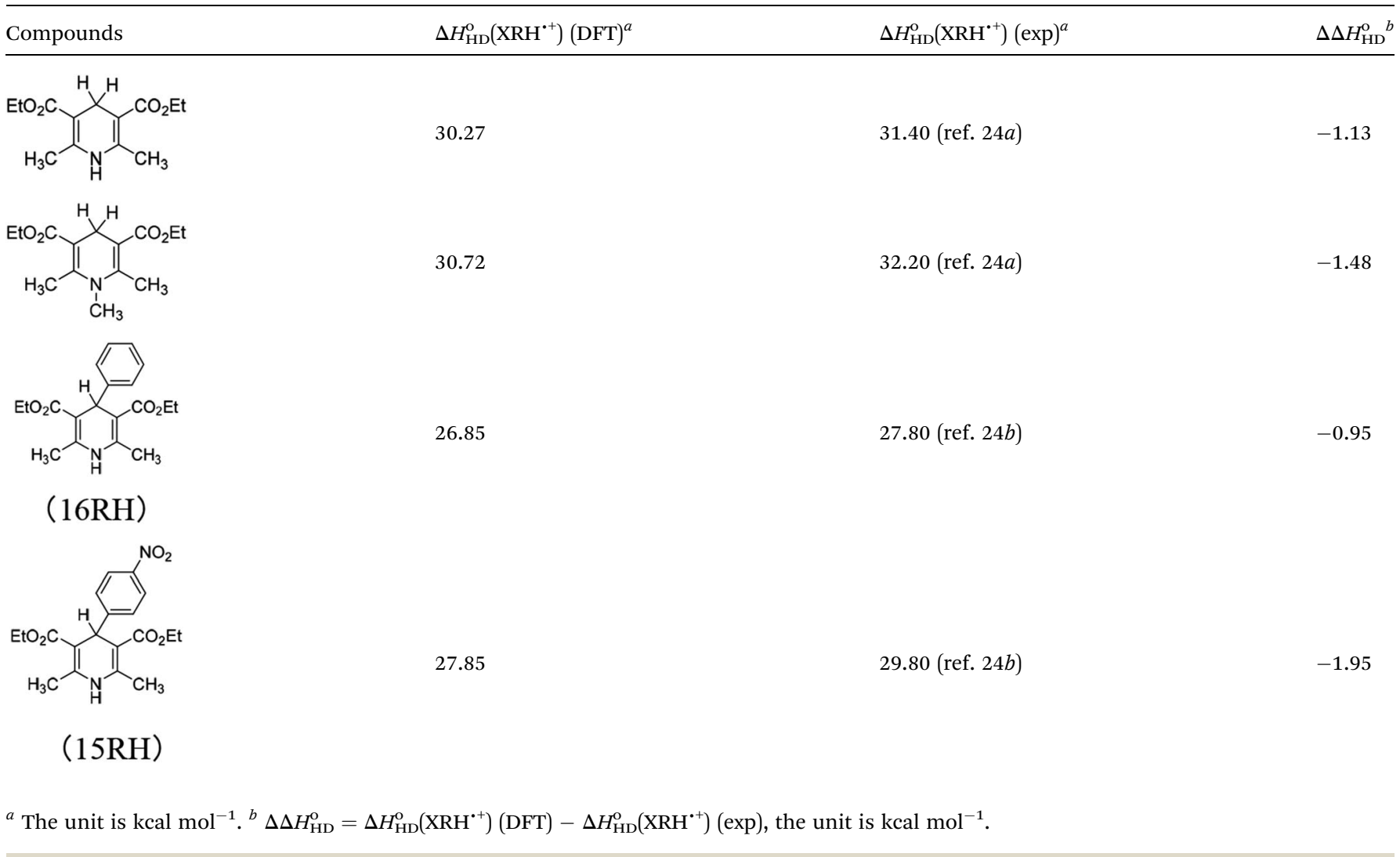

$\left[\Delta H_{\mathrm{RD}}^{\mathrm{O}}\left(\mathrm{XRH}^{\cdot+}\right)\right]$, and activation free energy of $\mathrm{XRH}^{\cdot+}$ releasing $\mathrm{R}^{\cdot}$ $\left[\Delta G_{\mathrm{RD}}^{\neq}\left(\mathrm{XRH}^{\cdot+}\right)\right]$ were computed in this work.

All quantum chemical calculations in this work were performed using Gaussian 09, ${ }^{19 a}$ and wave function analysis was performed using Multiwfn 3.7. ${ }^{19 b}$ First, find out the transition state of $\mathrm{XRH}^{\cdot+}$ releasing $\mathrm{R}^{\circ}$, and calculate the Gibbs free energy and enthalpy of reactant, transition state and product of each elemental step. Through analyzing the difference between reactant and product, free energy changes and enthalpy changes of $\mathrm{XRH}^{++}$releasing $\mathrm{R}^{\cdot}$ were obtained. The activation free energy and activation enthalpy could be obtained by comparing the reactant and the transition state in similar method.

First, the reactants, transition states and products of elemental step were geometrically optimized to convergence using the functional $\mathrm{B}^{2} \mathrm{LYP}^{20}$ and the basis set $6-31 \mathrm{G}(\mathrm{d}, \mathrm{p}){ }^{21}$ DFT-D3 empirical dispersion correction (BJ damping) ${ }^{22}$ was applied, and SMD solvent model ${ }^{23}$ (acetonitrile as the solvent) was used during the computation. After geometrical optimization, the vibration analysis was carried out using the same parameters. The results of vibration analysis showed that there is no imaginary frequency for all reactants and products; meanwhile, only one imaginary frequency was found for each transition state, and the direction of imaginary frequency was the same as that of $\mathrm{C}-\mathrm{C}$ bond stretch, indicating that the transition states were correct. Intrinsic reaction coordinate (IRC) was then calculated for each transition state, and electron spin density analysis of IRC-derived products showed that the cleavage products were alkyl radicals, not alkyl cations. Then, the thermodynamic correction was applied for each reactant, transition state and product at $298.15 \mathrm{~K}$. The free energy was obtained by adding the single point energy to the Gibbs free

Table 2 Thermodynamic data and activation free energy data of $\mathrm{XRH}^{\cdot+}$ releasing $\mathrm{R}^{\cdot}$

\begin{tabular}{|c|c|c|c|c|}
\hline $\mathrm{XRH}$ & $\Delta H_{\mathrm{RD}}^{\mathrm{o}}\left(\mathrm{XRH}^{\cdot+}\right)^{a}$ & $\Delta G_{\mathrm{RD}}^{\mathrm{o}}\left(\mathrm{XRH}^{\cdot+}\right)^{a}$ & $\Delta H_{\mathrm{RD}}^{\neq}\left(\mathrm{XRH}^{\cdot+}\right)^{a}$ & $\Delta G_{\mathrm{RD}}^{\neq}\left(\mathrm{XRH}^{\cdot+}\right)^{a}$ \\
\hline $1 \mathrm{RH}$ & 0.48 & -12.15 & 3.29 & 3.47 \\
\hline $2 \mathrm{RH}$ & 9.43 & -3.13 & 3.24 & 3.44 \\
\hline $3 \mathrm{RH}$ & 17.76 & 4.75 & 13.92 & 12.95 \\
\hline $4 \mathrm{RH}$ & 13.16 & -0.02 & 5.68 & 5.38 \\
\hline $5 \mathrm{RH}$ & 13.71 & 0.58 & 9.64 & 8.66 \\
\hline $6 \mathrm{RH}$ & 11.49 & -2.42 & 4.76 & 4.59 \\
\hline $7 \mathrm{RH}$ & 17.15 & 5.60 & 15.32 & 13.62 \\
\hline $8 \mathrm{RH}$ & 7.73 & -7.33 & 1.44 & 1.17 \\
\hline 9RH & 5.37 & -7.73 & 3.22 & 3.11 \\
\hline $10 \mathrm{RH}$ & 12.79 & -1.28 & 7.77 & 7.45 \\
\hline $11 \mathrm{RH}$ & 13.47 & -0.11 & 2.05 & 3.37 \\
\hline $12 \mathrm{RH}$ & 17.16 & 1.88 & 6.65 & 6.39 \\
\hline $13 \mathrm{RH}$ & 15.64 & 2.27 & 0.85 & 0.83 \\
\hline $14 \mathrm{RH}$ & 38.83 & 26.85 & 32.81 & 31.80 \\
\hline $15 \mathrm{RH}$ & 27.12 & 15.17 & 22.49 & 22.28 \\
\hline $16 \mathrm{RH}$ & 27.29 & 1.60 & 21.93 & 21.48 \\
\hline $17 \mathrm{RH}$ & 32.77 & 21.72 & 26.95 & 26.60 \\
\hline
\end{tabular}




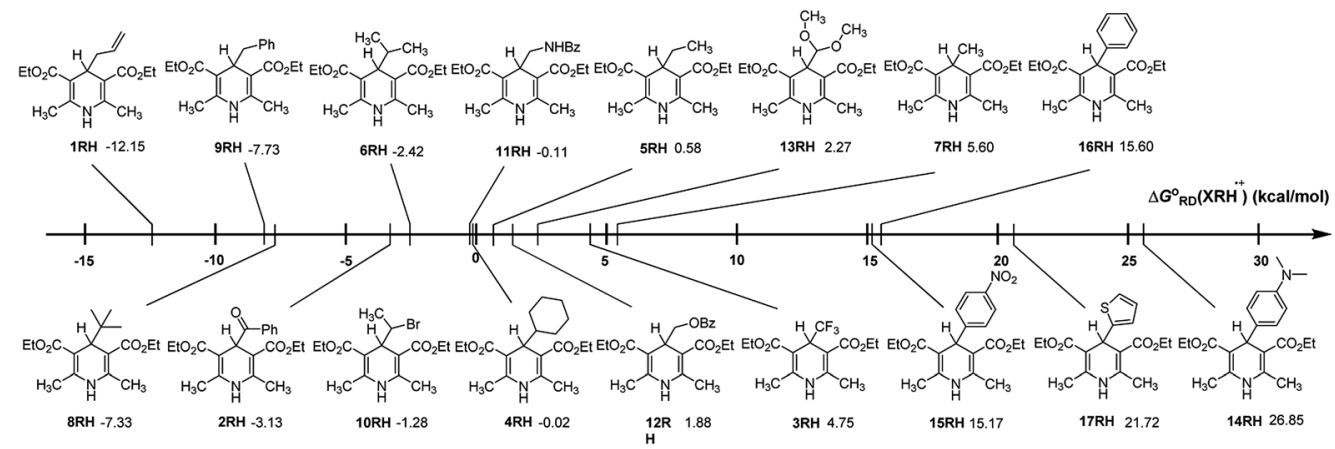

Fig. 1 Visual comparison of $\Delta G_{\mathrm{RD}}^{\circ}\left(\mathrm{XRH}^{++}\right)$among the $17 \mathrm{XRH}$ in acetonitrile at $298.15 \mathrm{~K}$.

energy correction value, and the enthalpy was obtained by adding the single point energy to the enthalpy correction value. Reaction rate constant $\left(k_{2}\right)$ was obtained by Eyring equation $\left[k_{2}\right.$ $\left.=\left(k_{\mathrm{B}} T / h\right) \exp \left(-\Delta G^{\neq} / R T\right)\right]$.

In order to verify the applicability and accuracy of the calculation method in this work, first we calculated the molar enthalpy changes of four $\mathrm{XRH}^{++}$releasing $\mathrm{H}^{*}$ using the above method (termed "calculation values" in this work). The molar enthalpy changes of $\mathrm{XRH}^{++}$releasing $\mathrm{H}^{*}$ determined by the calorimetric titration method in previous literature were termed "experimental values". ${ }^{24}$ The calculated value and the experimental value are listed in Table 1 , and the data shows that the deviation between calculated values and the experimental values is less than $2.0 \mathrm{kcal} \mathrm{mol}^{-1}$. Therefore, considering the experimental measurement error, it is appropriate to use the above calculation method to study the energy changes of $\mathrm{XRH}^{++}$ releasing $\mathrm{R}^{*}$, and the results obtained are accurate and reliable.

\section{Results and discussions}

The calculation results, $\Delta H_{\mathrm{RD}}^{\mathrm{o}}\left(\mathrm{XRH}^{\cdot+}\right), \Delta G_{\mathrm{RD}}^{\mathrm{o}}\left(\mathrm{XRH}^{\cdot+}\right)$ and $\Delta H_{\mathrm{RD}}^{\neq}\left(\mathrm{XRH}^{+}\right), \Delta G_{\mathrm{RD}}^{\neq}\left(\mathrm{XRH}^{+}\right)$are presented in Table 2.

\section{$3.1 \Delta G_{\mathrm{RD}}^{\mathrm{o}}\left(\mathrm{XRH}^{++}\right)$}

In order to discover the influence of structural factors on $\Delta G_{\mathrm{RD}}^{\mathrm{o}}\left(\mathrm{XRH}^{\cdot+}\right)$ values, the free energies changes of $17 \mathrm{XRH}^{+}$ releasing $\mathrm{R}^{\cdot}$ are listed in Fig. 1 for comparison. From Fig. 1, it is evident that the free energy changes of breaking $\mathrm{C}-\mathrm{C}$ bond for $\mathrm{XRH}^{++}$releasing $\mathrm{R}^{\cdot}$ varies greatly with the substituents, which ranges from -12.15 to $26.85 \mathrm{kcal} \mathrm{mol}^{-1}$. Among 4substituted Hantzsch ester structures investigated in this work, the Gibbs free energy of $\mathrm{XRH}^{\cdot+}$ releasing $\mathrm{R}^{\cdot}$ increased from $\Delta G^{\mathrm{o}} \ll 0 \quad\left(-12.15 \mathrm{kcal} \mathrm{mol}^{-1}\right)$ to $\Delta G^{\mathrm{o}} \gg$ $0\left(26.85 \mathrm{kcal} \mathrm{mol}^{-1}\right) .1 \mathrm{RH}^{++}$(4-allyl-substituted Hantzsch ester) has the lowest $\Delta G_{\mathrm{RD}}^{\mathrm{o}}\left(\mathrm{XRH}^{++}\right)$value as $-12.15 \mathrm{kcal} \mathrm{mol}^{-1}$, and $14 \mathrm{RH}^{++}$(4-dimethylaminophenyl substituted Hantzsch ester) has the highest value of $\Delta G_{\mathrm{RD}}^{\mathrm{o}}\left(\mathrm{XRH}^{\cdot+}\right)$ as $26.85 \mathrm{kcal} \mathrm{mol}^{-1}$, and the former is $39 \mathrm{kcal} \mathrm{mol}^{-1}$ lower than the latter. The thermodynamic data show that $1 \mathrm{RH}$ is the best alkylation reagents which spontaneously offers allyl radical in acetonitrile under the reaction condition of $298.15 \mathrm{~K}$; in contrast, 14RH cannot give 4-dimethylaminophenyl group in chemical reactions. Such a large range of $\Delta G_{\mathrm{RD}}^{\mathrm{o}}\left(\mathrm{XRH}^{\cdot+}\right)$ values $(-12.15-$ $26.85 \mathrm{kcal} \mathrm{mol}^{-1}$ ) indicates that the $\mathrm{R}$ group in the parent structure of XRH has a great influence on the value of $\Delta G_{\mathrm{RD}}^{\mathrm{o}}\left(\mathrm{XRH}^{++}\right)$, and the strength of $\mathrm{C}-\mathrm{C}$ bond varies greatly in different structures of $\mathrm{XRH}^{+}$.

Through comprehensive analysis and evaluation of $\Delta G_{\mathrm{RD}}^{\mathrm{o}}\left(\mathrm{XRH}^{+}\right)$, the results show that $\mathrm{XRH}^{++}$is possible (but not necessarily) to be an excellent $\mathrm{R}^{\cdot}$ donors which are determined by the $\mathrm{R}$ substituents in 4-position. If $\mathrm{R}$ substituents in $\mathrm{XRH}^{++}$ are not aromatic substituents, $\mathrm{XRH}^{++}$would be used as alkylation reagent; in contrast, if $\mathrm{R}$ substituents in $\mathrm{XRH}^{++}$are aromatic substituents, $\mathrm{XRH}^{++}$would not be used as $\mathrm{R}^{\cdot}$ donors.

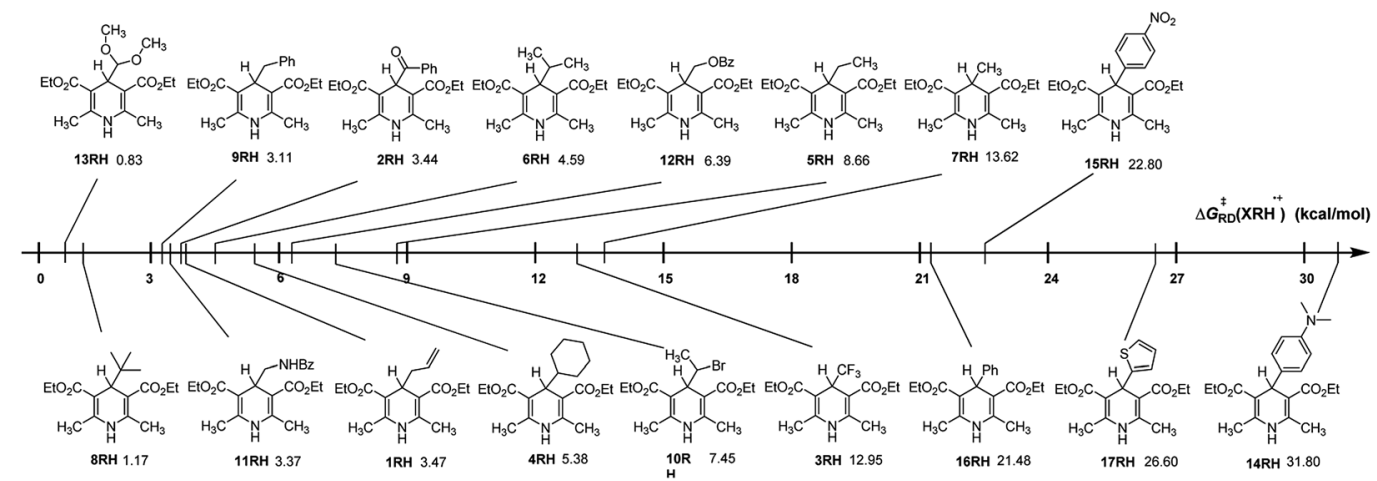

Fig. 2 Visual comparison of $\Delta G_{\mathrm{RD}}^{\neq}\left(\mathrm{XRH}^{\cdot+}\right)$ among the $17 \mathrm{XRH}$ in acetonitrile at $298.15 \mathrm{~K}$. 


\section{$3.2 \Delta G_{\mathrm{RD}}^{\neq}\left(\mathrm{XRH}^{\cdot+}\right)$}

From columns 5 in Table 2, it is clear that the $\Delta G_{\mathrm{RD}}^{\neq}\left(\mathrm{XRH}^{\cdot+}\right)$ values of $\mathrm{XRH}^{\cdot+}$ releasing $\mathrm{R}^{\cdot}$ range from 0.83 to $31.80 \mathrm{kcal} \mathrm{mol}^{-1}$. As shown in Fig. $2, \Delta G_{\mathrm{RD}}^{\neq}\left(\mathrm{XRH}^{\cdot+}\right)$ value of $13 \mathrm{RH}^{\cdot+}$ releasing $\mathrm{R}^{\cdot}$ is the smallest $\left(0.83 \mathrm{kcal} \mathrm{mol}^{-1}\right)$; hence, the rate constant of $13 \mathrm{RH}^{\cdot+}$ releasing $\mathrm{R}^{\cdot}\left(1.53 \times 10^{12} \mathrm{M}^{-1} \mathrm{~s}^{-1}\right)$ is greater than diffusion speed $\left(10^{10} \mathrm{M}^{-1} \mathrm{~s}^{-1}\right)$; while $\Delta G_{\mathrm{RD}}^{\neq}\left(\mathrm{XRH}^{\cdot+}\right)$ value of $14 \mathrm{RH}^{*^{+}}$releasing $\mathrm{R}^{\cdot}$ is the largest $\left(31.80 \mathrm{kcal} \mathrm{mol}^{-1}\right)$, so the rate constant of $14 \mathrm{RH}^{\cdot+}$ releasing $\mathrm{R}^{\cdot}$ is lowest with $2.87 \times 10^{-12} \mathrm{M}^{-1} \mathrm{~S}^{-1}$ at $298.15 \mathrm{~K}$ in acetonitrile, which indicates that the reaction of $14 \mathrm{RH}^{\circ+}$ releasing $\mathrm{R}^{\circ}$ is extremely slow, and therefore $14 \mathrm{RH}$ cannot be used as $\mathrm{R}^{\circ}$ donor in chemical reaction. The predicted rate constants of $\mathrm{XRH}^{\cdot+}$ releasing $\mathrm{R}^{\cdot}$ in this work range from $2.87 \times 10^{-12}$ to $1.53 \times 10^{12}\left(\mathrm{M}^{-1} \mathrm{~s}^{-1}\right)$. Thus, it can be seen that there are many important chemical reactions in vivo or in vitro whose rates cannot be directly measured using experimental methods up to now. The reason is that some reactions are too fast, some are too slow and some have no detectable signals, etc. Because the accuracy of the calculation results is verified by experimental measured values, the rate constants of $\mathrm{XRH}^{\cdot+}$ releasing $\mathrm{R}^{*}$ that cannot be measured experimentally can be estimated by the activation energy calculation method used in this work. Among the $17 \mathrm{XRH}$ structures examined, $\Delta G_{\mathrm{RD}}^{\neq}\left(\mathrm{XRH}^{\cdot+}\right)$ values of $13 \mathrm{XRH}(1 \mathrm{RH}-13 \mathrm{RH})$ are less than $16 \mathrm{kcal} \mathrm{mol}{ }^{-1}\left(k_{2}=6.29 \times 10^{2} \mathrm{M}^{-1} \mathrm{~s}^{-1}\right.$ at $\left.298.15 \mathrm{~K}\right)$, $\Delta G_{\mathrm{RD}}^{\neq}\left(\mathrm{XRH}^{\cdot+}\right)$ values of $4 \mathrm{XRH}(14 \mathrm{RH}-17 \mathrm{RH})$ span from 21.48 to $31.80 \mathrm{kcal} \mathrm{mol}^{-1}\left(1.07 \times 10^{-3}\right.$ to $1.07 \times 10^{-11} \mathrm{M}^{-1} \mathrm{~s}^{-1}$ at $298.15 \mathrm{~K})$. The $\Delta G_{\mathrm{RD}}^{\neq}\left(\mathrm{XRH}^{\cdot+}\right)$ values indicate that $1 \mathrm{RH}-13 \mathrm{RH}$ could be selected as $\mathrm{R}^{\cdot}$ donor in chemical reactions, while 14RH-17RH cannot provide $\mathrm{R}^{\circ}$ as alkylation reagents. Further taking their structures into consideration, we find that $\mathrm{R}$ substituents in $14 \mathrm{RH}-17 \mathrm{RH}$ are aromatic substituents and the $\Delta G_{\mathrm{RD}}^{\neq}\left(\mathrm{XRH}^{\cdot+}\right)$ of $\mathrm{XRH}^{\cdot+}$ releasing $\mathrm{R}^{\cdot}$ all larger than $21.4 \mathrm{kcal} \mathrm{mol}^{-1}$ which means 4-aromatic-group substituted Hantzsch esters cannot be used as $\mathrm{R}^{*}$ donors. If R substituents in $\mathrm{XRH}^{\cdot+}$ are not aromatic substituents, $\mathrm{XRH}^{\cdot+}(1 \mathrm{RH}-13 \mathrm{RH})$ would be good $\mathrm{R}^{\cdot}$ donors in radical reactions.

\subsection{Entropy change and activation entropy change}

Since Gibbs free energies $\left[\Delta G_{\mathrm{RD}}^{\mathrm{o}}\left(\mathrm{XRH}^{\cdot+}\right)\right]$, enthalpy changes $\left[\Delta H_{\mathrm{RD}}^{\mathrm{o}}\left(\mathrm{XRH}^{\cdot+}\right)\right]$, activation energies $\left[\Delta G_{\mathrm{RD}}^{\neq}\left(\mathrm{XRH}^{\cdot+}\right)\right]$ and activation enthalpy changes $\left[\Delta H_{\mathrm{RD}}^{\neq}\left(\mathrm{XRH}^{\cdot+}\right)\right]$ were obtained now, we calculated the entropy changes $\left(\Delta S_{\mathrm{RD}}^{\mathrm{o}}\right)$ and activation entropy changes $\left(\Delta S_{\mathrm{RD}}^{\neq}\right)$of $\mathrm{XRH}^{\cdot+}$ releasing $\mathrm{R}^{\cdot}$ which are listed in Table 3.

From Table 3, it is found that the entropy changes of $\mathrm{XRH}^{{ }^{+}}$ releasing $\mathrm{R}^{\cdot}, \Delta S_{\mathrm{RD}}^{\mathrm{o}}$, range from 38.75 to $51.26 \mathrm{cal} \mathrm{mol}^{-1} \mathrm{~K}^{-1}$, and the activation entropy changes of $\mathrm{XRH}^{+}$releasing $\mathrm{R}^{\cdot}$, $\Delta S_{\mathrm{RD}}^{\neq}$, range from -4.42 to $5.69 \mathrm{cal} \mathrm{mol}^{-1} \mathrm{~K}^{-1} . \Delta S_{\mathrm{RD}}^{\mathrm{o}}$ are positive values (cal $\mathrm{mol}^{-1} \mathrm{~K}^{-1}$ ), which indicates that the chemical process of $\mathrm{XRH}^{++}$releasing $\mathrm{R}^{\cdot}$ is the large entropy increase process. While the span of activation entropy changes of $\mathrm{XRH}^{{ }^{+}}$ releasing $\mathrm{R}^{\cdot}, \Delta S_{\mathrm{RD}}^{\neq}$, is less than $\pm 5 \mathrm{cal} \mathrm{mol}^{-1} \mathrm{~K}^{-1}$, which indicates that the chemical structures of $\mathrm{XRH}^{\cdot+}$ do not change greatly in the transition state.
Table 3 Entropy changes and activation entropy changes of $\mathrm{XRH}^{\cdot+}$ releasing $R^{*}$

\begin{tabular}{lrr}
\hline $\mathrm{XRH}$ & $\Delta S_{\mathrm{RD}}^{\mathrm{o}}{ }^{a}$ & \multicolumn{1}{c}{$\Delta S_{\mathrm{RD}}^{\neq b}$} \\
\hline $1 \mathrm{RH}$ & 42.39 & -0.60 \\
$2 \mathrm{RH}$ & 42.13 & -0.66 \\
$3 \mathrm{RH}$ & 43.65 & 3.26 \\
$4 \mathrm{RH}$ & 44.22 & 0.99 \\
$5 \mathrm{RH}$ & 44.07 & 3.28 \\
$6 \mathrm{RH}$ & 46.69 & 0.58 \\
$7 \mathrm{RH}$ & 38.75 & 5.69 \\
$8 \mathrm{RH}$ & 50.53 & 0.91 \\
$9 \mathrm{RH}$ & 43.98 & 0.36 \\
$10 \mathrm{RH}$ & 47.24 & 1.09 \\
$11 \mathrm{RH}$ & 45.57 & -4.42 \\
$12 \mathrm{RH}$ & 51.26 & 0.87 \\
$13 \mathrm{RH}$ & 44.85 & 0.08 \\
$14 \mathrm{RH}$ & 40.21 & 3.37 \\
$15 \mathrm{RH}$ & 40.12 & 0.72 \\
$16 \mathrm{RH}$ & 39.24 & 1.50 \\
$17 \mathrm{RH}$ & 37.09 & 1.18
\end{tabular}

${ }^{a}$ From the equation, $\Delta S=(\Delta H-\Delta G) / T$, the unit is cal $\mathrm{mol}^{-1} \mathrm{~K}^{-1}$.

${ }^{b}$ From the equation, $\Delta S^{\neq}=\left(\Delta H^{\neq}-\Delta G^{\ddagger}\right) / T$, the unit is cal mol ${ }^{-1} \mathrm{~K}^{-1}$.

\subsection{Main factors affecting free energy changes and activation free energy changes of $\mathrm{XRH}^{\cdot+}$ releasing $\mathrm{R}^{\cdot}$}

3.4.1 Thermodynamic driving force and activation free energy. Because the XRH structure investigated in this work is 1,4dihydropyridine compounds, only the R substituents in 4-position are different. In order to further explore the intrinsic relationship between the thermodynamic driving forces $\left[\Delta G_{\mathrm{RD}}^{\mathrm{O}}\left(\mathrm{XRH}^{\cdot+}\right)\right]$ and the activation energy $\left[\Delta G_{\mathrm{RD}}^{\neq}\left(\mathrm{XRH}^{{ }^{+}}\right)\right]$, relationships between them are shown in Fig. 3. It can be seen from Fig. 3 that there is a certain correlation between the thermodynamic driving force and activation free energy changes of $\mathrm{XRH}^{+}$releasing $\mathrm{R}^{\circ}$, that is, $\Delta G_{\mathrm{RD}}^{\neq}\left(\mathrm{XRH}^{\cdot+}\right)$ increases along with the increase of $\Delta G_{\mathrm{RD}}^{\mathrm{o}}\left(\mathrm{XRH}^{\cdot+}\right)$. But for all chemical reactions, there is no good linear correlation between $\Delta G^{\neq}$and $\Delta G^{\text {o }}$. This phenomenon shows that the thermodynamic driving force has an important influence on the activation energy, but it is not the only decisive factor. ${ }^{25}$

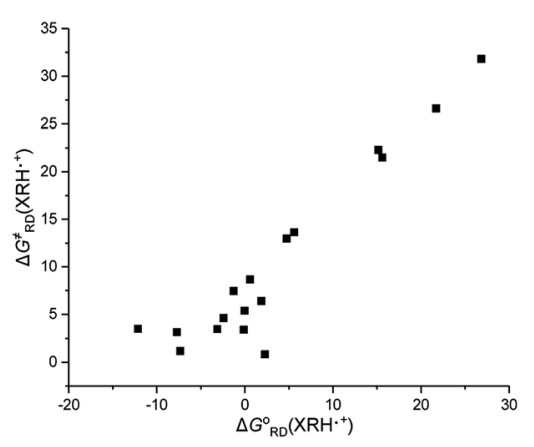

Fig. 3 Relationship between the activation free energies of $17 \mathrm{XRH}^{\cdot+}$ releasing $\mathrm{R}^{\cdot}$ and the corresponding free energy changes of $\mathrm{XRH}^{\cdot+}$ releasing $\mathrm{R}^{*}$ in acetonitrile at $298.15 \mathrm{~K}$. 


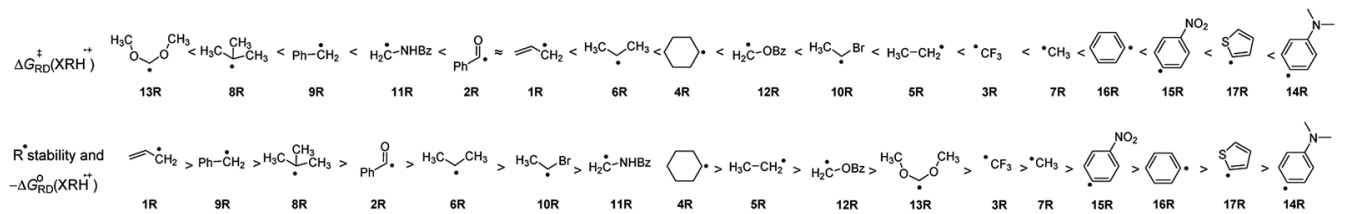

Fig. 4 The order of $\mathrm{R}^{*}$ stability and activation free energies of $17 \mathrm{XRH}^{\cdot+}$ releasing $\mathrm{R}^{\text {* }}$.

3.4.2 The stability of $\mathrm{R}^{\cdot}$ and $\Delta G_{\mathrm{RD}}^{\neq}\left(\mathrm{XRH}^{\cdot+}\right)$. It can be seen from the above discussion that many $\mathrm{XRH}$ with different structures can be used as $\mathrm{R}^{\cdot}$ donor. $\Delta G_{\mathrm{RD}}^{\neq}\left(\mathrm{XRH}^{\cdot+}\right)$ values range from 0.83 to $13.62 \mathrm{kcal} \mathrm{mol}^{-1}$, and the difference between the fastest and slowest rate constant is $10^{10}$. Through the previous discussion, we have known that the thermodynamic driving force is an important factor affecting the activation energy of the reaction. Then, does it exist an internal relationship between the stability of $\mathrm{R}^{\cdot}$ and the reaction activity of $\mathrm{XRH}^{\cdot+}$ releasing $\mathrm{R}^{\text {. }}$ $\Delta G_{\mathrm{RD}}^{\neq}\left(\mathrm{XRH}^{\cdot+}\right)$ ? Considering the chemical process of $\mathrm{XRH}^{{ }^{+}}$ releasing $\mathrm{R}^{\cdot}$ with different structure, $\mathrm{XRH}^{\cdot+} \rightarrow \mathrm{XH}^{+}+\mathrm{R}^{\cdot}$, it is found that the values of molar free energy of $\mathrm{XRH}^{++}$releasing $\mathrm{R}^{\cdot}$ $\left[\Delta G_{\mathrm{RD}}^{\mathrm{o}}\left(\mathrm{XRH}^{\cdot+}\right)\right]$ do reflect the relative stabilities of $\mathrm{R}^{\circ}$. The smaller $\Delta G_{\mathrm{RD}}^{\mathrm{o}}\left(\mathrm{XRH}^{\cdot+}\right)$ is, the more stability $\mathrm{R}^{*}$ is. On the basis of $\Delta G_{\mathrm{RD}}^{\mathrm{o}}\left(\mathrm{XRH}^{\cdot+}\right)$ values computed in this work, the $\mathrm{R}^{\cdot}$ stability order in $1 \mathrm{RH}$ to $17 \mathrm{RH}$ molecules investigated in this work is $1 \mathrm{R}$ $>9 \mathrm{R}>8 \mathrm{R}>2 \mathrm{R}>6 \mathrm{R}>10 \mathrm{R}>11 \mathrm{R}>4 \mathrm{R}>5 \mathrm{R}>16 \mathrm{R}>12 \mathrm{R}>13 \mathrm{R}>3 \mathrm{R}$ $>7 \mathrm{R}>15 \mathrm{R}>17 \mathrm{R}>4 \mathrm{R}$ (Fig. 4). But according to the $\Delta G_{\mathrm{RD}}^{\neq}\left(\mathrm{XRH}^{\cdot+}\right)$ values, the order of reactivity is $13 \mathrm{R}>8 \mathrm{R}>9 \mathrm{R}>$ $11 \mathrm{R}>2 \mathrm{R}>6 \mathrm{R}>4 \mathrm{R}>12 \mathrm{R}>10 \mathrm{R}>5 \mathrm{R}>3 \mathrm{R}>7 \mathrm{R}>16 \mathrm{R}>15 \mathrm{R}>17 \mathrm{R}$ $>14 \mathrm{R}$ (Fig. 4). It is clear that there are significant differences between the order of stability of $\mathrm{R}^{\cdot}$ and the order of $\Delta G_{\mathrm{RD}}^{\neq}\left(\mathrm{XRH}^{\cdot+}\right)$, and the stability of $\mathrm{R}^{\cdot}$ is not the decisive factor of $\Delta G_{\mathrm{RD}}^{\neq}\left(\mathrm{XRH}^{\cdot+}\right)$. The results also show that the influence of structural factors on $\Delta G_{\mathrm{RD}}^{\neq}\left(\mathrm{XRH}^{\cdot+}\right)$ is multifaceted and complicated.

3.4.3 Substituent effect. For $14 \mathrm{RH}, 16 \mathrm{RH}$ and $15 \mathrm{RH}$, the R substituents at the 4-positions are $p$-dimethylaminophenyl, phenyl and $p$-nitrophenyl respectively, all of which are benzene ring structures with different $p$-substituents. Dimethylamino group $\left(\sigma_{\mathrm{p}}=-0.83\right)$ and nitro group $\left(\sigma_{\mathrm{p}}=-0.78\right)$ are relatively strong electron-donating and electron-withdrawing groups respectively. We designed these two groups in order to change the ability of $\mathrm{XRH}^{\cdot+}$ releasing $\mathrm{R}^{\cdot}$ to provide aromatic free radicals by tremendously changing the electronegativity of substituents. The relevant data are compared in Fig. 5. According to Fig. 5, the following conclusions can be made: (1) when the 4position is a strong electron-donating group (dimethylamino group), free energy changes and activation energy changes of $\mathrm{XRH}^{+}$releasing $\mathrm{R}^{\cdot}$ increased significantly (about 5$10 \mathrm{kcal} \mathrm{mol}^{-1}$ ). (2) When the 4-position is a strong electronwithdrawing group (nitro group), free energy changes and activation energy changes of $\mathrm{XRH}^{\cdot+}$ releasing $\mathrm{R}^{\cdot}$ changed slightly $\left(<1.5 \mathrm{kcal} \mathrm{mol}^{-1}\right)$. The above calculation results show that the change of electronegativity of benzene ring does not make XHR the donor of aromatic benzene free radicals. No matter it is electron-donating group or electron-withdrawing group, the abilities of $\mathrm{XHR}^{\cdot+}$ releasing $\mathrm{R}^{\cdot}$ are decreased, meanwhile the effect of electron-donating group on ability of $\mathrm{XHR}^{\cdot+}$ releasing $\mathrm{R}^{\cdot}$ is greater than that of electron-withdrawing group. ${ }^{26}$

3.4.4 Influence of steric hindrance and stability of $\mathbf{R}^{\circ}$. For 4-substituted Hantzsch esters 7RH, 5RH, 6RH and 8RH, R substituent groups are methyl, ethyl, isopropyl and tert-butyl (Fig. 6), respectively. The steric resistance of the substituents increases gradually with increasing of the stability of $\mathrm{R}^{\circ}$. From Fig. 6 , it is found that $\Delta G_{\mathrm{RD}}^{\mathrm{o}}\left(\mathrm{XRH}^{\cdot+}\right)$ of $\mathrm{XRH}^{\cdot+}$ releasing $\mathrm{R}^{\cdot}$ decrease from 5.60 to $-7.33 \mathrm{kcal} \mathrm{mol}^{-1}, \Delta G_{\mathrm{RD}}^{\neq}\left(\mathrm{XRH}^{++}\right)$of $\mathrm{XRH}^{\cdot+}$ releasing $\mathrm{R}^{\cdot}$ decrease from 13.62 to $1.17 \mathrm{kcal} \mathrm{mol}^{-1}$, as gradually increasing of steric hindrance and stability of $\mathrm{R}^{\cdot}$ from $7 \mathrm{RH}^{\cdot+}$ to $8 \mathrm{RH}^{\cdot+}$ (Fig. 6).<smiles>CCOC(=O)C1=C(C)NC(C)=C(C(=O)OCC)C1c1ccc(N(C)C)cc1</smiles>

14RH<smiles>CCOC(=O)C1=C(C)NC(C)=C(C(=O)OCC)C1c1ccccc1</smiles>

16RH<smiles>CCOC(=O)C1=C(C)NC(C)=C(C(=O)OCC)C1c1ccc([N+](=O)[O-])cc1</smiles>

15.60

21.48
15.17

22.28

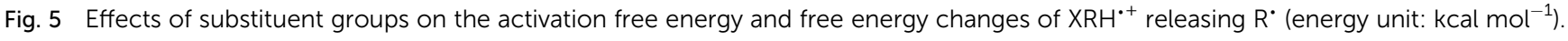




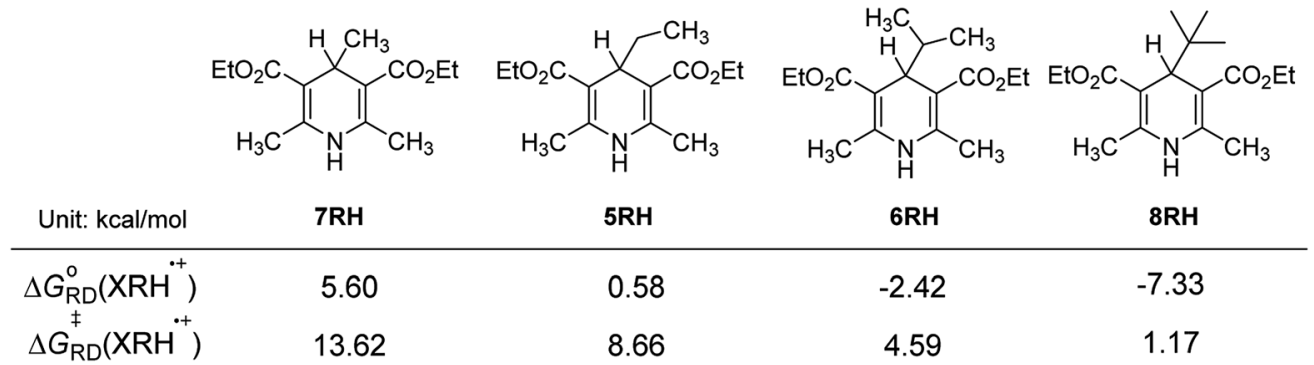

Fig. 6 Effects of size and stability of substituent groups on the activation free energy and free energy changes of $\mathrm{XRH}^{\cdot+}$ releasing $\mathrm{R}^{*}(\mathrm{energy}$ unit: kcal mol${ }^{-1}$ ).

Table 4 Diagnoses of reactivity of $\mathrm{XRH}$ using as radical agent according to $\Delta G_{\mathrm{RD}}^{\neq}\left(\mathrm{XRH}^{\cdot+}\right)$

\begin{tabular}{|c|c|c|c|c|}
\hline XRH & $\Delta G_{\mathrm{RD}}^{\mathrm{o}}\left(\mathrm{XRH}^{\cdot+}\right)^{a}$ & $\Delta G_{\mathrm{RD}}^{\neq}\left(\mathrm{XRH}^{\cdot+}\right)^{a}$ & $k_{2}^{b}$ & Diagnose \\
\hline $1 \mathrm{RH}$ & -12.15 & 3.47 & $1.76 \times 10^{10}$ & Excellent $\mathrm{R}^{\cdot}$ donor \\
\hline $2 \mathrm{RH}$ & -3.13 & 3.44 & $1.85 \times 10^{10}$ & Excellent $\mathrm{R}^{\bullet}$ donor \\
\hline $4 \mathrm{RH}$ & -0.02 & 5.38 & $6.99 \times 10^{8}$ & Excellent $\mathrm{R}^{\bullet}$ donor \\
\hline $5 \mathrm{RH}$ & 0.58 & 8.66 & $2.74 \times 10^{6}$ & Excellent $\mathrm{R}^{\circ}$ donor \\
\hline $6 \mathrm{RH}$ & -2.42 & 4.59 & $2.66 \times 10^{9}$ & Excellent $\mathrm{R}^{\cdot}$ donor \\
\hline $9 \mathrm{RH}$ & -7.73 & 3.11 & $3.24 \times 10^{10}$ & Excellent $\mathrm{R}^{\cdot}$ donor \\
\hline $10 \mathrm{RH}$ & -1.28 & 7.45 & $2.12 \times 10^{7}$ & Excellent $\mathrm{R}^{\cdot}$ donor \\
\hline 11RH & -0.11 & 3.37 & $2.09 \times 10^{10}$ & Excellent $\mathrm{R}^{\cdot}$ donor \\
\hline $12 \mathrm{RH}$ & 1.88 & 6.39 & $1.27 \times 10^{8}$ & Excellent $\mathrm{R}^{\cdot}$ donor \\
\hline $13 \mathrm{RH}$ & 2.27 & 0.83 & $1.53 \times 10^{12}$ & Excellent $\mathrm{R}^{\cdot}$ donor \\
\hline $14 \mathrm{RH}$ & 26.85 & 31.80 & $2.87 \times 10^{-11}$ & Not $\mathrm{R}^{\cdot}$ donor \\
\hline
\end{tabular}

${ }^{a}$ The energy unit is kcal $\mathrm{mol}^{-1}{ }^{b}$ The unit is $\mathrm{M}^{-1} \mathrm{~s}^{-1}$.

\subsection{Judgment criteria of whether an XRH is a great alkylation reagent}

Considering activation free energy of $\mathrm{XRH}^{+}$releasing $\mathrm{R}^{\cdot}$ $\left[\Delta G_{\mathrm{RD}}^{\neq}\left(\mathrm{XRH}^{\cdot+}\right)\right]$, the judgment criteria of XRH being a good $\mathrm{R}^{\cdot}$ donor can be concluded reasonably (Table 4). Generally, in practice, an activation free energy $\left(\Delta G^{\neq}\right)$of $21 \mathrm{kcal} \mathrm{mol}^{-1}$ is usually used as a criteria in determining whether a reaction could easily occur at room temperature, according to the Transition State Theory (TST); ${ }^{27}$ an activation free energy of $21 \mathrm{kcal} \mathrm{mol}^{-1}$ corresponds to a half-life of $\sim 4.5 \mathrm{~min}$ and a $97 \%$ completion time of $22.3 \mathrm{~min}$ at room temperature, which indicate that the reaction can be completed within an acceptable time. Accordingly, the following predictions can be made: (1) if the value of $\Delta G_{\mathrm{RD}}^{\neq}\left(\mathrm{XRH}^{*}\right)$ is larger than $21.0 \mathrm{kcal} \mathrm{mol}^{-1}\left(k_{2}\right.$ $<2.42 \times 10^{-3} \mathrm{M}^{-1} \mathrm{~s}^{-1}$ ), XRH could not be used as alkylation reagent, like $14 \mathrm{RH}-17 \mathrm{RH}$. (2) If the value of $\Delta G_{\mathrm{RD}}^{\neq}\left(\mathrm{XRH}^{\cdot+}\right)$ is larger than $17.5 \mathrm{kcal} \mathrm{mol}^{-1}\left(k_{2} \leq 1 \mathrm{M}^{-1} \mathrm{~s}^{-1}\right)$, but smaller than $21.0 \mathrm{kcal} \mathrm{mol}^{-1}\left(k_{2} \geq 2.42 \times 10^{-3} \mathrm{M}^{-1} \mathrm{~s}^{-1}\right) \mathrm{XRH}$ is a weak alkylation reagent. (3) If the value of $\Delta G_{\mathrm{RD}}^{\neq}\left(\mathrm{XRH}^{\cdot+}\right)$ is larger than $12.0 \mathrm{kcal} \mathrm{mol}^{-1}\left(k_{2} \leq 9.71 \times 10^{3} \mathrm{M}^{-1} \mathrm{~s}^{-1}\right)$, but smaller than $17.5 \mathrm{kcal} \mathrm{mol}^{-1}\left(k_{2} \geq 1 \mathrm{M}^{-1} \mathrm{~s}^{-1}\right) \mathrm{XRH}$ is a medium alkylation reagent, like $3 \mathrm{RH}$ and $7 \mathrm{RH}$. (4) If the value of $\Delta G_{\mathrm{RD}}^{\neq}\left(\mathrm{XRH}^{++}\right)$is smaller than $12.0 \mathrm{kcal} \mathrm{mol}^{-1}\left(k_{2}>9.71 \times 10^{3} \mathrm{M}^{-1} \mathrm{~s}^{-1}\right)$, XRH is an excellent alkylation reagent, like $8 \mathrm{RH}-13 \mathrm{RH}$. Since $\Delta G_{\mathrm{RD}}^{\neq}\left(\mathrm{XRH}^{{ }^{+}}\right)$has no simple correlation with the $\mathrm{XRH}^{\prime}$ structure, the electronegativity and steric resistance, it is difficult to judge whether XRH can provide $\mathrm{R}^{\cdot}$ in chemical reactions solely by experience. The calculation method and results provided in this work are helpful to guide the application of XRH as a free radical donor in organic synthesis.

\section{Conclusions}

In this work, 4 characteristic physical parameters, $\Delta H_{\mathrm{RD}}^{\mathrm{o}}\left(\mathrm{XRH}^{\cdot+}\right), \Delta G_{\mathrm{RD}}^{\mathrm{o}}\left(\mathrm{XRH}^{\cdot+}\right), \Delta H_{\mathrm{RD}}^{\neq}\left(\mathrm{XRH}^{++}\right), \Delta G_{\mathrm{RD}}^{\neq}\left(\mathrm{XRH}^{\cdot+}\right)$ of 17 important XRH releasing $\mathrm{R}^{\cdot}$ were calculated using DFT method. After careful discussion of the relevant thermodynamic and kinetic data, the following conclusions can be made: (1) through comprehensive analysis and evaluation of $\Delta G^{\mathrm{o}}$ and $\Delta G^{*}$, it is found that $\mathrm{XRH}^{++}$is possible (but not necessarily) to be an excellent $\mathrm{R}^{\cdot}$ donors which are determined by the $\mathrm{R}$ substituents in 4-position. (2) If $\mathrm{R}$ substituents in XRH are not aromatic groups, $\mathrm{XRH}^{++}$can release $\mathrm{R}^{\cdot}$ as key intermediates, 
therefore $\mathrm{XRH}$ could be used as alkylation reagents. In contrast, if $\mathrm{R}$ substituents in $\mathrm{XRH}$ are aromatic substituents, the key intermediates $\mathrm{XRH}^{\cdot+}$ could not release aromatic radical in chemical reactions, so XRH with aromatic substituents could not be used as alkylation reagents. (3) The thermodynamic driving force (Gibbs free energy) has an important influence on the activation energy, but it is not the only decisive factor. (4) There are significant differences between the order of $\mathrm{R}^{\circ}$ stability and the order of $\Delta G_{\mathrm{RD}}^{\neq}\left(\mathrm{XRH}^{\cdot+}\right)$, and the stability of $\mathrm{R}^{\cdot}$ is not the decisive factor of $\Delta G_{\mathrm{RD}}^{\neq}\left(\mathrm{XRH}^{*}\right)$. In addition, the influence of structural factors on $\Delta G_{\mathrm{RD}}^{\neq}\left(\mathrm{XRH}^{\cdot+}\right)$ is multifaceted and complicated. (5) Change of electronegativity of benzene ring does not make XHR be an aromatic free radical donor. (6) According to $\Delta G_{\mathrm{RD}}^{\neq}\left(\mathrm{XRH}^{\cdot+}\right)$ values, the kinetic ability of $\mathrm{XRH}^{\cdot+}$ releasing $\mathrm{R}^{\cdot}$ can be predicted reasonably. (1) If the value of $\Delta G_{\mathrm{RD}}^{\neq}\left(\mathrm{XRH}^{\cdot+}\right)$ is larger than $21.0 \mathrm{kcal} \mathrm{mol}^{-1}, \mathrm{XRH}$ could not be used as an alkylation reagent. (2) If the value of $\Delta G_{\mathrm{RD}}^{\neq}\left(\mathrm{XRH}^{\cdot+}\right)$ is larger than $17.5 \mathrm{kcal} \mathrm{mol}^{-1}$, but smaller than $21.0 \mathrm{kcal} \mathrm{mol}^{-1}$, $\mathrm{XRH}$ is a weak alkylation reagent. (3) If the value of $\Delta G_{\mathrm{RD}}^{\neq}\left(\mathrm{XRH}^{\cdot+}\right)$ is larger than $12.0 \mathrm{kcal} \mathrm{mol}^{-1}$, but smaller than $21.0 \mathrm{kcal} \mathrm{mol}^{-1}, \mathrm{XRH}$ is a medium alkylation reagent. (4) If the value of $\Delta G_{\mathrm{RD}}^{\neq}\left(\mathrm{XRH}^{\cdot+}\right)$ is smaller than $12.0 \mathrm{kcal} \mathrm{mol}^{-1}, \mathrm{XRH}$ is an excellent alkylation reagent.

It is known that the reaction conditions of XRH using as alkylation reagents are quite complex, and this paper focuses on the intrinsic properties of key intermediate $\mathrm{XRH}^{++}$releasing $\mathrm{R}^{\circ}$. Since $\Delta G_{\mathrm{RD}}^{\neq}\left(\mathrm{XRH}^{\cdot+}\right)$ has no simple correlation with the XRH's structure, the electronegativity and steric resistance, it is difficult to judge whether XRH can be used as an alkylation reagent in chemical reactions solely by experience. The calculation method and results provided in this work are helpful to guide the application of XRH as a free radical donor in organic synthesis.

\section{Conflicts of interest}

The authors declare no competing financial interests.

\section{Acknowledgements}

This study was supported by NSFC cultivation project of Jining Medical University (JYP2018KJ18 and JYP2019KJ25) and College Students' Innovative Training Plan Program of Jining Medical University (cx2020106).

\section{References}

1 A. Hantzsch, Ber. Dtsch. Chem. Ges., 1881, 14, 1637.

2 Reviews: (a) C. Zheng and S.-L. You, Transfer Hydrogenation with Hantzsch Esters and Related Organic Hydride Donors, Chem. Soc. Rev., 2012, 41, 2498-2518; (b) S.-L. You, Recent Developments in Asymmetric Transfer Hydrogenation with Hantzsch Esters: A Biomimetic Approach, Chem.-Asian J., 2007, 2, 820-827; (c) S. G. Ouellet, A. M. Walji and D. W. C. Macmillan, Enantioselective Organocatalytic Transfer Hydrogenation Reactions using Hantzsch Esters, Acc. Chem. Res., 2007, 40, 1327-1339; (d) M. Rueping,
J. Dufour and F. R. Schoepke, Advances in Catalytic Metalfree Reductions: from Bio-inspired Concepts to Applications in the Organocatalytic Synthesis of Pharmaceuticals and Natural Products, Green Chem., 2011, 13, 1084-1105.

3 (a) M. O. Konev, L. Cardinale and A. J. Wangelin, CatalystFree N-Deoxygenation by Photoexcitation of Hantzsch Ester, Org. Lett., 2020, 22, 1316-1320; (b) S. Zhang, G. Li, L. Li, X. Deng, G. Zhao, X. Cui and Z. Tang, AlloxanCatalyzed Biomimetic Oxidations with Hydrogen Peroxide or Molecular Oxygen, ACS Catal., 2020, 10, 245-252; (c) C. T. Ser, H. Yang and M. W. Wong, IodoimidazoliniumCatalyzed Reduction of Quinoline by Hantzsch Ester: Halogen Bond or Brønsted Acid Catalysis, J. Org. Chem., 2019, 84, 10338-10348; (d) Q.-A. Chen, M.-W. Chen, C.-B. Yu, L. Shi, D.-S. Wang, Y. Yang and Y.-G. Zhou, Biomimetic Asymmetric Hydrogenation: In Situ Regenerable Hantzsch Esters for Asymmetric Hydrogenation of Benzoxazinones, J. Am. Chem. Soc., 2011, 133, 16432-16435.

4 (a) S. B. Nagode, R. Kant and N. Rastogi, Hantzsch EsterMediated Benzannulation of Diazo Compounds under Visible Light Irradiation, Org. Lett., 2019, 21, 6249-6254; (b) G. Hamasaka, H. Tsuji, M. Ehara and Y. Uozumi, Mechanistic Insight into the Catalytic Hydrogenation of Nonactivated Aldehydes with a Hantzsch Ester in the Presence of a Series of Organoboranes: NMR and DFT Studies, RSC Adv., 2019, 9, 10201-10210; (c) R. Tang, Z. Shao, J. Wang, Z. Liu, Y.-M. Li and Y. Shen, Iron(II)Catalyzed Radical Addition to Aldimines with Hantzsch Ester as a Two-Hydrogen Atom Donor, J. Org. Chem., 2019, 84, 8177-8184; (d) J. A. Leitch, T. Rogova, F. Duarte and D. J. Dixon, Dearomative Photocatalytic Construction of Bridged 1,3-Diazepanes, Angew. Chem., Int. Ed., 2020, 59, 4121-4130.

5 G. Li, R. Chen, L. Wu, Q. Fu, X. Zhang and Z. Tang, Alkyl Transfer from C-C Cleavage, Angew. Chem., Int. Ed., 2013, 52, 8432-8436.

6 Reviews: (a) P.-Z. Wang, J.-R. Chen and W.-J. Xiao, Hantzsch esters: an emerging versatile class of reagents in photoredox catalyzed organic synthesis, Org. Biomol. Chem., 2019, 17, 6936-6951; (b) S. Ye and J. Wu, 4-Substituted Hantzsch Esters as Alkylation Reagents in Organic Synthesis, Acta Chim. Sin., 2019, 77, 814-831.

7 (a) K. Nakajima, S. Nojima and Y. Nishibayashi, Nickel- and Photoredox-Catalyzed Cross-Coupling Reactions of Aryl Halides with 4-Alkyl-1,4-dihydropyridines as Formal Nucleophilic Alkylation Reagents, Angew. Chem., Int. Ed., 2016, 55, 14106-14110; (b) D.-L. Zhu, Q. Wu, H.-Y. Li, H.-X. Li and J.-P. Lang, Hantzsch Ester as a Visible-Light Photoredox Catalyst for Transition-Metal-Free Coupling of Arylhalides and Arylsulfinates, Chem.-Eur. J., 2020, 26(16), 3484-3488; (c) J. Li, X.-E. Yang, S.-L. Wang, L.-L. Zhang, X.-Z. Zhou, S.-Y. Wang and S.-J. Ji, Visible-Light-Promoted Cross-Coupling Reactions of 4-Alkyl-1,4-dihydropyridines with Thiosulfonate or Selenium Sulfonate: A Unified 
Approach to Sulfides, Selenides, and Sulfoxides, Org. Lett., 2020, 22(12), 4908-4913.

8 (a) Z.-Y. Song, C.-L. Zhang and S. Ye, Visible light promoted coupling of alkynyl bromides and Hantzsch esters for the synthesis of internal alkynes, Org. Biomol. Chem., 2019, 17, 181-185; (b) H. Chen, D. Anand and L. Zhou, Photoredox Defluorinative Alkylation of 1-Trifluoromethyl Alkenes and 1,3-Butadienes with 1,4-Dihydropyridines as Alkylation Reagents, Asian J. Org. Chem., 2019, 8(5), 661-664; (c) H.-W. Du, J. Sun, Q.-S. Gao, J.-Y. Wang, H. Wang, Z. Xu and M.-D. Zhou, Synthesis of Monofluoroalkenes through Visible-Light-Promoted Defluorinative Alkylation of gemDifluoroalkenes with 4-Alkyl-1,4-dihydropyridines, Org. Lett., 2020, 22(4), 1542-1546.

9 (a) Z.-J. Wang, S. Zheng, J. K. Matsui, Z. Lu and G. A. Molander, Desulfonative photoredox alkylation of Nheteroaryl sulfones- an acid-free approach for substituted heteroarene synthesis, Chem. Sci., 2019, 10, 4389-4393; (b) Á. Gutiérrez-Bonet, C. Remeur, J. K. Matsui and G. A. Molander, Late-Stage $\mathrm{C}-\mathrm{H}$ Alkylation of Heterocycles and 1,4-Quinones via Oxidative Homolysis of 1,4Dihydropyridines, J. Am. Chem. Soc., 2017, 139(35), 1225112258; (c) L. Buzzetti, A. Prieto, S. R. Roy and P. Melchiorre, Radical-Based C-C Bond-Forming Processes Enabled by the Photoexcitation of 4-Alkyl-1,4dihydropyridines, Angew. Chem., Int. Ed., 2017, 56, 1503915043.

10 (a) A. Gutierrez-Bonet, J. C. Tellis, J. K. Matsui, B. A. Vara and G. A. Molander, 1,4-Dihydropyridines as Alkyl Radical Precursors: Introducing the Aldehyde Feedstock to Nickel/ Photoredox Dual Catalysis, ACS Catal., 2016, 6, 8004-8008; (b) A. Dumoulin, J. K. Matsui, A. Gutierrez-Bonet and G. A. Molander, Synthesis of Non-Classical Arylated CSaccharides through Nickel/Photoredox Dual Catalysis, Angew. Chem., Int. Ed., 2018, 57, 6614-6618; (c) S. O. Badir, A. Dumoulin, J. K. Matsui and G. A. Molander, Synthesis of Reversed C-Acyl Glycosides through Ni/Photoredox Dual Catalysis, Angew. Chem., Int. Ed., 2018, 57, 6610-6613.

11 (a) H.-H. Zhang, J.-J. Zhao and S. Yu, Enantioselective Allylic Alkylation with 4-Alkyl-1,4-dihydro-pyridines Enabled by Photoredox/Palladium Cocatalysis, J. Am. Chem. Soc., 2018, 140(49), 16914-16919; (b) S. Liang, T. Kumon, R. A. Angnes, M. Sanchez, B. Xu and G. B. Hammond, Synthesis of Alkyl Halides from Aldehydes via Deformylative Halogenation, Org. Lett., 2019, 21(10), 38483854.

12 (a) R. A. Angnes, C. Potnis, S. Liang, C. R. D. Correia and G. B. Hammond, Photoredox-Catalyzed Synthesis of Alkylaryldiazenes: Formal Deformylative C-N Bond Formation with Alkyl Radicals, J. Org. Chem., 2020, 85(6), 4153-4164; (b) S. Zhang, Y. Li, J. Wang, X. Hao, K. Jin, R. Zhang and C. Duan, A photocatalyst-free photo-induced denitroalkylation of $\beta$-nitrostyrenes with 4 -alkyl substituted Hantzsch esters at room temperature, Tetrahedron Lett., 2020, 61(14), 151721; (c) J. Wang, Y.-B. Pang, N. Tao, R.-S. Zeng and Y. Zhao, Mn-Enabled Radical-Based Alkyl-
Alkyl Cross-Coupling Reaction from 4-Alkyl-1,4dihydropyridines, J. Org. Chem., 2019, 84(23), 15315-15322.

13 (a) S. Liang, R. A. Angnesa, C. S. Potnisb and G. B. Hammond, Photoredox catalyzed $\mathrm{C}\left(\mathrm{sp}^{3}\right)-\mathrm{C}(\mathrm{sp})$ coupling of dihydropyridines and alkynylbenziodoxolones, Tetrahedron Lett., 2019, 60(45), 151230; (b) X. Shen, L. Qian and S. Yu, Photoredox/palladium-cocatalyzed enantioselective alkylation of secondary benzyl carbonates with 4-alkyl-1,4-dihydropyridines, Sci. China: Chem., 2020, 63(5), 687-691; (c) K. Zhang, L.-Q. Lu, Y. Jia, Y. Wang, F.-D. Lu, F. Pan and W.-J. Xiao, Exploration of a Chiral Cobalt Catalyst for Visible-Light-Induced Enantioselective Radical Conjugate Addition, Angew. Chem., Int. Ed., 2019, 131(38), 13509-13513.

14 (a) Q.-Y. Wu, Q.-Q. Min, G.-Z. Ao and F. Liu, Radical alkylation of para-quinone methides with 4-substituted Hantzsch esters/nitriles via organic photoredox catalysis, Org. Biomol. Chem., 2018, 16, 6391-6394; (b) H.-H. Zhang and S. Yu, Radical Alkylation of Imines with 4-Alkyl-1,4dihydropyridines Enabled by Photoredox/Brønsted Acid Cocatalysis, J. Org. Chem., 2017, 82, 9995-10006; (c) F. F. Assis, X. Huang, M. Akiyama, R. A. Pilli and E. Meggers, Visible-Light-Activated Catalytic Enantioselective $\beta$-Alkylation of $\alpha, \beta$-Unsaturated 2-Acyl Imidazoles Using Hantzsch Esters as Radical Reservoirs, $J$. Org. Chem., 2018, 83, 10922-10932.

15 (a) X. Liu, R. Liu, J. Dai, X. Cheng and G. Li, Application of Hantzsch Ester and Meyer Nitrile in Radical Alkynylation Reactions, Org. Lett., 2018, 20, 6906-6909; (b) J. K. Matsui, S. B. Lang, D. R. Heitz and G. A. Molander, PhotoredoxMediated Routes to Radicals: The Value of Catalytic Radical Generation in Synthetic Methods Development, ACS Catal., 2017, 7, 2563-2575; (c) F. Gu, W. Huang, X. Liu, W. Chen and X. Cheng, Substituted Hantzsch Esters as Versatile Radical Reservoirs in Photoredox Reactions, Adv. Synth. Catal., 2018, 360(5), 925-931.

16 (a) W. Chen, Z. Liu, J. Tian, J. Li, J. Ma, X. Cheng and G. Li, Building Congested Ketone: Substituted Hantzsch Ester and Nitrile as Alkylation Reagents in Photoredox Catalysis, J. Am. Chem. Soc., 2016, 138, 12312-12315; (b) X. Wang, M. Yang, W. Xie, X. Fan and J. Wu, Photoredox-catalyzed hydrosulfonylation reaction of electron deficient alkenes with substituted Hantzsch esters and sulfur dioxide, Chem. Commun., 2019, 55, 6010-6013; (c) B. R. McDonald and K. A. Scheidt, Intermolecular Reductive Radical-Radical Couplings of Arylidene Malonates via Lewis Acid/ Photoredox Cooperative Catalysis, Org. Lett., 2018, 20(21), 6877-6881.

17 (a) X. Wang, H. Li, G. Qiu and J. Wu, Substituted Hantzsch esters as radical reservoirs with the insertion of sulfur dioxide under photoredox catalysis, Chem. Commun., 2019, 55, 2062-2065; (b) J. P. Phelan, S. B. Lang, J. Sim, S. Berritt, A. J. Peat, K. Billings, L. Fan and G. A. Molander, Open-Air Alkylation Reactions in Photoredox-Catalyzed DNAEncoded Library Synthesis, J. Am. Chem. Soc., 2019, 141, 3723-3732; (c) T. Leeuwen, L. Buzzetti, L. A. Perego and P. Melchiorre, A Redox-Active Nickel Complex that Acts as 
an Electron Mediator in Photochemical Giese Reactions, Angew. Chem., Int. Ed., 2019, 58, 4953-4957.

18 (a) C. Verrier, N. Alandini, C. Pezzetta, M. Moliterno, L. Buzzetti, H. B. Hepburn, A. Vega-Peñaloza, M. Silvi and P. Melchiorre, Direct Stereoselective Installation of Alkyl Fragments at the $\beta$-Carbon of Enals via Excited Iminium Ion Catalysis, ACS Catal., 2018, 8, 1062-1066; (b) G. Goti, B. Bieszczad, A. Vega-Penaloza and P. Melchiorre, Stereocontrolled Synthesis of 1,4-Dicarbonyl Compounds by Photochemical Organocatalytic Acyl Radical Addition to Enals, Angew. Chem., Int. Ed., 2019, 58, 1213-1217; (c) K. Nakajima, Y. Zhang and Y. Nishibayashi, Alkylation Reactions of Azodicarboxylate Esters with 4-Alkyl-1,4Dihydropyridines under Catalyst-Free Conditions, Org. Lett., 2019, 21(12), 4642-4645.

19 (a) M. J. Frisch, G. W. Trucks, H. B. Schlegel, et al., Gaussian 09, 2013; (b) T. Lu and F. Chen, Multiwfn: A Multifunctional Wavefunction Analyzer, J. Comput. Chem., 2012, 33, 580-592.

20 (a) A. D. Becke, Density-Functional Thermochemistry. 3. The Role of Exact Exchange, J. Chem. Phys., 1993, 98(7), 56485652; (b) P. J. Stephens, F. J. Devlin, C. F. Chabalowski and M. J. Frisch, Ab-initio Calculation of Vibrational Absorption and Circular-dichroism Spectra using Densityfunctional Force-fields, J. Phys. Chem., 1994, 98, 1162311627.

21 (a) R. Ditchfield, W. J. Hehre and J. A. Pople, Self-Consistent Molecular Orbital Methods. 9. Extended Gaussian-type Basis for Molecular-orbital Studies of Organic Molecules, J. Chem. Phys., 1971, 54, 724; (b) W. J. Hehre, R. Ditchfield and J. A. Pople, Self-Consistent Molecular Orbital Methods. 12. Further Extensions of Gaussian-type Basis Sets for Use in Molecular-orbital Studies of Organic-molecules, J. Chem. Phys., 1972, 56, 2257; (c) P. C. Hariharan and J. A. Pople, Influence of Polarization Functions on Molecular-orbital Hydrogenation Energies, Theor. Chem. Acc., 1973, 28, 213222.

22 S. Grimme, S. Ehrlich and L. Goerigk, Effect of the Damping Function in Dispersion Corrected Density Functional Theory, J. Comput. Chem., 2011, 32, 1456-1465.

23 A. V. Marenich, C. J. Cramer and D. G. Truhlar, Universal Solvation Model Based on Solute Electron Density and on a Continuum Model of the Solvent Defined by the Bulk Dielectric Constant and Atomic Surface Tensions, J. Phys. Chem. B, 2009, 113(18), 6378-6396.

24 (a) X.-Q. Zhu, H.-R. Li, Q. Li, T. Ai, J.-Y. Lu, Y. Yang and J.-P. Cheng, Determination of the $\mathrm{C} 4-\mathrm{H}$ Bond Dissociation Energies of NADH Models and Their Radical Cations in Acetonitrile, Chem.-Eur. J., 2003, 9(4), 871-880; (b) X.-Q. Zhu, Q.-Y. Liu, Q. Chen and L.-R. Mei, Hydride, Hydrogen, Proton, and Electron Affinities of Imines and Their Reaction Intermediates in Acetonitrile and Construction of Thermodynamic Characteristic Graphs (TCGs) of Imines as a "Molecule ID Card", J. Org. Chem., 2010, 75, 789-808.

25 (a) Y.-H. Fu, G.-B. Shen, Y. Li, L. Yuan, J.-L. Li, L. Li, A.-K. Fu, J. Chen, B.-L. Chen, L. Zhu and X.-Q. Zhu, Realization of Quantitative Estimation for Reaction Rate Constants Using only One Physical Parameter for Each Reactant, ChemistrySelect, 2017, 2, 904-925; (b) X.-Q. Zhu, F.-H. Deng, J.-D. Yang, X.-T. Li, Q. Chen, N.-P. Lei, F.-K. Meng, X.-P. Zhao, S.-H. Han, E.-J. Hao and Y.-Y. Mu, A classical but new kinetic equation for hydride transfer reactions, Org. Biomol. Chem., 2013, 11, 6071-6089.

26 (a) S.-M. Si, Y.-H. Fu and X.-Q. Zhu, Determination and Comparison of Thermodynamic Driving Forces of Elementary Steps for the Reductions of Alkynes and the Corresponding Alkenes in Acetonitrile, J. Phys. Chem. C, 2015, 119, 62-74; (b) X.-Q. Zhu, M.-T. Zhang, A. Yu, C.-H. Wang and J.-P. Cheng, Hydride, Hydrogen Atom, Proton, and Electron Transfer Driving Forces of Various Five-Membered Heterocyclic Organic Hydrides and Their Reaction Intermediates in Acetonitrile, J. Am. Chem. Soc., 2008, 130, 2501-2516; (c) Y. Cao, S.-C. Zhang, M. Zhang, G.-B. Shen and X.-Q. Zhu, Determination of Thermodynamic Affinities of Various Polar Olefins as Hydride, Hydrogen Atom, and Electron Acceptors in Acetonitrile, J. Org. Chem., 2013, 78, 7154-7168.

27 B. C. Garrett and D. G. Truhlar, Transition State Theory, in Encyclopedia of Computational Chemistry, John Wiley \& Sons, Hoboken, NJ, USA, 1998, pp. 3094-3104. 